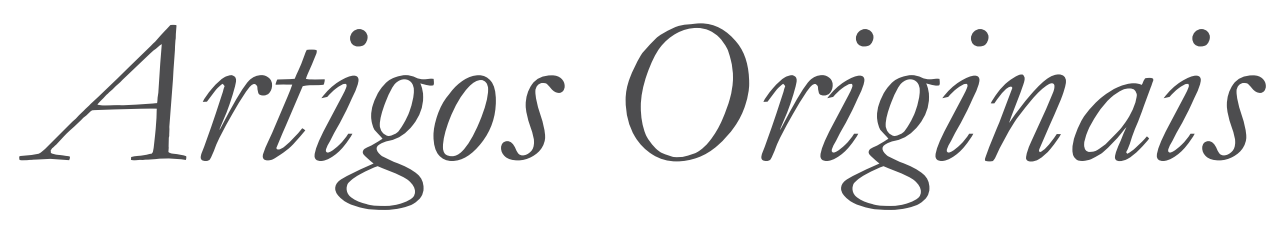




\title{
TERRITÓRIO E GOVERNANÇA: AS PRINCIPAIS CONTRIBUIÇÕES DA GEOGRAFIA PARA PENSAR O DESENVOLVIMENTO
}

\author{
José Renato Ribeiro ${ }^{1}$ \\ Ricardo Nagliati Toppan ${ }^{2}$
}

\section{RESUMO}

Muito além de um tema estudado pela Geografia, nas últimas quatro décadas, o processo de globalização vem configurando-se como um elemento crucial na readequação de teorias e conceitos básicos das ciências sociais, sobretudo aquelas que consideram o espaço como um método de análise. Esse fenômeno apresenta aos espaços novos imperativos, novas regulações, possibilidades e limites, o que torna necessário o desenvolvimento e a discussão de novos elementos capazes de compreender a realidade e também responder positivamente a tal processo. Assim, dentre os ineditismos espaciais construídos por esse período, a relação entre o global e o local tornou-se muito mais articulada, provocada, sobretudo, pela dinâmica concorrencial global, o que resultou na necessidade de se considerar novos aspectos territoriais que fazem a diferença nesse jogo. Por tudo isso, o objetivo deste artigo consiste em problematizar a relação entre o território e o desenvolvimento, chamando a atenção para a importância da governança como um recurso importante e presente em determinados contextos espaciais ou territoriais. O objetivo desse artigo é discutir as principais contribuições da Geografia para os estudos acerca do desenvolvimento, trazendo autores que discutem a temática a partir de diferentes correntes do pensamento geográfico e econômico. Para tanto, destacamos que os resultados teóricos aqui expostos são resultantes de discussões e de uma pesquisa realizada pelo grupo de pesquisa do CNPq "Estruturas de Governança e Desenvolvimento Territorial", intitulada "Modalidades da Governança Territorial no Estado de São Paulo", pesquisa que foi financiada pela Fundação de Amparo à Pesquisa do Estado de São Paulo. Com isso, consideramos que as diferentes estratégias de governança para com o desenvolvimento sejam recursos intransferíveis, dada as suas características próprias adquiridas do território em que se constitui. É possível concluir que o território deva ser entendido como um conceito essencial nos estudos sobre o desenvolvimento

Palavras-chave: Território; Desenvolvimento; Governança.

\footnotetext{
1. Instituto de Geociências e Ciências Exatas - UNESP- Rio Claro. Correspondência joserenatorbr@gmail.com

2. Instituto de Geociências e Ciências Exatas - UNESP- Rio Claro
} 


\title{
TERRITORY AND GOVERNANCE: THE MAIN CONTRIBUTIONS OF GEOGRAPHY FOR THINKING ABOUT DEVELOPMENT
}

\begin{abstract}
Much more than a theme studied by Geography, in the last four decades, the process of globalization has emerged as a crucial element in the readjustment of theories and basic concepts of the social sciences, especially those which consider the space as a method of analysis. This phenomenon introduces to new spaces imperatives, new regulations, possibilities and limits, which requires the development and the discussion of new elements capable of understanding reality and also of responding positively to such a process. So, among the spatial uniqueness constructed by this period, the relationship between the global and the local became much more articulated, provoked, moreover, by the global competitive dynamics, resulting in the necessity of considering new territorial aspects which make the difference in this game. For these reasons, the objective of this paper is to problematize the relationship between territory and development, calling the attention to the importance of governance as an important and present resource in determined spacial or territorial contexts. The aim of this paper is to discuss the main contributions of Geography to studies on development, bringing authors who discuss the subject from different currents of geographic and economic thought. For this purpose, we emphasize that the theoretical results shown here are the result of discussions and of a survey conducted by a CNPq's research group on "Structures of Governance and Territorial Development", entitled "Modalities of Territorial Governance in São Paulo", research that was funded by FAPESP. Thus, we consider that the different governance strategies for the development are non-transferable resources given their specific characteristics acquired in the territory in which they are constituted. It is possible to conclude that territory must be regarded as an essential concept in the studies on development.
\end{abstract}

Keywords: Territory; Development; Governance.

\section{INTRODUÇÃO}

Dentre as mudanças ocasionadas pela Globalização estudadas pelas ciências que consideram relevante, a dimensão espacial está o novo contexto de competitividade regional, fincado cada vez mais pela especialização produtiva. As regiões que conseguiram sucesso nesse ambiente competitivo mais hostil passaram a mobilizar seus recursos territoriais, transferíveis e intransferíveis, demonstrando assim novas estratégias para o crescimento econômico, desenvolvimento de recursos humanos e fortalecimento de uma rede de relações e pactos entre os atores sociais existentes no espaço.

Para tanto, esse comportamento das regiões em alcançar papel de protagonista na Globalização, contrariando o discurso homogeneizador até então disseminado por ela, um conjunto profundo de mudanças foram realizadas no interior da estrutura administrativa do Estado. No Brasil, a principal ferramenta para esse fim foi à promulgação da Constituição de 1988, a primeira Constituinte pós-regime militar, que realizou um conjunto de reformas institucionais nas funções do Estado finalizadas por meio da criação do Ministério da Administração e Reforma do Estado (MARE), em 1995, passando-o de uma ação interventora e produtora de políticas centralizadas de desenvolvimento para um Estado regulador. 
Essas reformas agiram na transferência de serviços, recursos e competências do governo federal para os níveis estaduais e municipais.

Com o processo de redemocratização do Brasil e a formação da Constituição Cidadã (SAMPAIO, 2008), foi possível considerar que o país entraria em uma nova concepção de políticas para o desenvolvimento regional, dado pelo início de uma descentralização política e um novo dinamismo na estrutura fiscal. Sader (2013) considera que o fim da ditadura não representou a democratização da sociedade brasileira, muito menos a redução das desigualdades sociais, sobretudo com o início das políticas neoliberais que começavam a emergir nos anos seguintes, a partir do governo de Fernando Collor de Melo. Assim, embora esse novo processo jurídico e institucional brasileiro pós-ditadura tenha dado a possibilidade, num primeiro momento, de garantia dos direitos, autonomia e representatividade das regiões frente às grandes desigualdades socioeconômicas historicamente presentes no país, ela evidenciara alguns dilemas no desenvolvimento regional, desde políticas perversas iniciadas por um período de guerra fiscal entre as localidades, concebendo as regiões mais vulneráveis às regras do mercado, até a ausência de uma política ou programa nacional liderado pelo poder federal.

É preciso entender que o atual período se configura como uma relação dual entre o global e o local, acentuando-se a dinâmica concorrencial, tornando necessário considerar alguns elementos territoriais que fazem a diferença nesse jogo. Em um cenário político-econômico caracterizado pelo pós-fordismo em que o Estado não mantém a rigor políticas keynesianas, a provisão do desenvolvimento não deve ser conduzida pela "mão invisível" do mercado ao atuar sobre seu território. O papel do Estado nessa nova conduta descentralizada deve conduzir a uma política coordenada espacial e setorialmente, com autonomia e sem deixar de adquirir um caráter endógeno. As mudanças no regime de produção e na forma de organização dos espaços numa tentativa de garantir competitividade e especificidades são o que Benko (2001) denomina de um processo de glocalização, entendido pelo autor como uma articulação expandida dos territórios locais em relação à economia mundial, sublinhando a persistência de uma inscrição espacial dos fenômenos econômicos, sociais e culturais (BENKO, 2001, p.9).

Em reação a todo esse contexto, materializam no cenário nacional algumas políticas para organizar estruturas institucionais e projetos de desenvolvimento de caráter endógeno, vinculados a atores, recursos e conhecimentos locais, definindo-se alguns territórios. Criam-se assim, formas de coordenação ou regulação parciais de cadeias produtivas e do processo de desenvolvimento socioeconômico dos territórios, de forma mais ampla e efetiva. Estas novas formas de coordenação, denominada de governança territorial, vem se mostrando como um requisito importante para com o planejamento, se tornando uma aposta não apenas com potencialidades para um novo modelo de desenvolvimento mais participativo, mas também como caminhos para (re)pensar o conceito de território.

Por tudo isso, o objetivo desse artigo é discutir a relação entre o território e desenvolvimento, chamando a atenção para a importância da governança como um recurso importante e presente em determinados contextos espaciais. Para tanto, o texto está organizado em cinco seções, iniciado por essa introdução. $\mathrm{Na}$ segunda seção, buscamos discutir o conceito de território dentro da ciência geográfica e a sua contribuição para pensar o desenvolvimento. Na terceira, abordamos o papel da governança como alavanca para o desenvolvimento, situando-a como um elemento fulcral para conceber o território. Já na quarta seção são apresentadas algumas possibilidades de governança existentes no Brasil. Na quinta e última são feitas as considerações finais acerca do tema.

A metodologia proposta nesse artigo trata-se de um trabalho de cunho teórico, mas que se baseia em elementos empíricos (exemplos de modalidades de governança) para demonstrar a contribuição e a materialização do conceito de território construído pela Geografia e de governança para pensar o desenvolvimento. Os elementos empíricos são fruto de pesquisas e discussões sistematizadas resultadas do grupo de pesquisa interdisciplinar do Conselho Nacional de Desenvolvimento Científico e Tecnológico 
$(\mathrm{CNPq})$ "Estruturas de governança e desenvolvimento territorial" da Universidade Estadual Paulista "Júlio de Mesquita Filho" (UNESP), campus de Rio Claro, que realizou a pesquisa "Modalidades da Governança Territorial no Estado de São Paulo", financiada pela Fundação de Amparo à Pesquisa do Estado de São Paulo. Assim sendo, s resultados dessa pesquisa contribuíram consideravelmente para as discussões apresentadas nesse artigo que além de buscar explanar as principais contribuições da Geografia, busca construir um diálogo entre essa ciência e todos os campos do conhecimento que problematizam a temática do desenvolvimento econômico e social.

\section{As contribuições da geografia para o desenvolvimento: o conceito de território}

A ciência geográfica tem na globalização um instigante campo de estudo, principalmente na sua ênfase econômica, que segundo Benko \& Pecqueur (2001) conheceu uma verdadeira renovação e que possibilitou o retorno da noção de Território às análises econômicas. Este é um conceito com diferentes concepções teóricas e que demonstra certa complexidade, vista sua constituição material e imaterial do processo histórico, e que, portanto, apresenta relações tempo e espaço específicos.

Considerando o território como um dos principais conceitos que procura responder a problemática que envolve a relação entre sociedade e o seu espaço, Haesbaert (2004) percebe-o através de suas dimensões política (porção do espaço delimitado e controlado através do qual é exercido um poder - Estado), cultural (prioriza a dimensão simbólica e mais subjetiva de um grupo em relação ao seu espaço vivido) econômica (enfatizando a dimensão espacial das relações econômicas, fonte de recursos e/ou incorporado no embate entre classes sociais) e natural (relação sociedade e natureza, principalmente em que se refere ao comportamento natural dos homens em determinados ambientes físicos). Assim, o autor concebe essa definição de território como uma perspectiva integradora, pois este só poderia o ser entendido a partir das diferentes dimensões sociais, até naturais. No entanto, é importante ponderar que tal entendimento carece de precisão ou objetividade, pois conceber o território dessa forma tão abrangente pode resultar na perda da importância da noção de poder (fundamental para a definição do conceito), confundindo-se ainda com a noção de espaço, tão complexo para a Geografia.

Já o pensamento de Saquet (2011), que dialoga com a ideia apresentada acima, percebe o território como produto da relação sociedade - natureza, constituindo como um campo de forças que envolvem relações sociais permeadas pela dimensão econômica, política e cultural (EPC) que são determinadas historicamente. Em sua análise, o território é produto de seu referente processo de territorialização, considerando a sua construção espaço-temporal realizado por um determinado grupo social através do exercício do poder.

A fim de elucidar a infinidade do universo conceitual sobre o território, Santos (2002) desenvolve a noção de território usado e não apenas o território propriamente dito, concebido como objeto de análise social da Geografia. Segundo ele, o território seria um conjunto de sistemas naturais e artificiais, abrangendo pessoas, instituições e as empresas, sendo um dos elementos no qual constitui o Estado-Nação. Nesse sentido, o território é entendido em suas divisões políticas, seu legado histórico e seu atual conteúdo econômico, financeiro, fiscal e normativo, no qual é marcado pela Globalização e denominado por ele de Período Técnico-Científico-Informacional. (Santos, 2001, 2002). Levantando a questão global-local, Santos $(2002$, p.84) considera que "é desse modo que ele constitui, pelos lugares, aquele quadro da vida social onde tudo é interdependente, levando também, à fusão entre o local, o global invasor e o nacional sem defesa (no caso Brasil)".

É importante pensar o território enquanto "nosso quadro de vida", que Santos (1994) diz ser 
fundamental para que seja refutado o risco da alienação, da perda do sentido da existência individual e coletiva, sendo com isso uma perda ou renúncia ao futuro. Também, de maneira mais incisiva, Santos (1994) considera o território como:

Suporte de redes que transportam regras e normas utilitárias, parciais, egoísticas (do ponto de vista dos atores hegemônicos), as verticalidades, enquanto as horizontalidades hoje enfraquecidas são obrigadas, com suas forças limitadas, a levar em conta a totalidade dos atores (SANTOS, 1994, p 19)

Completando o raciocínio, ainda afirma em outro momento que "a arena de oposição entre o mercado - que singulariza - e a sociedade civil - que generaliza - é o território, em suas diversas dimensões e escala" (Santos, 1998, p. 18). Apesar da concepção de território usado ser passível de crítica e refutação, a ideia de território normatizado, presente em sua teoria sobre o espaço geográfico, torna-se importante para pensarmos no poder do território - local frente a eventos externos ou globais.

Elementos tais como a política, a cultura e a economia são centrais ao considerarmos as causas e as consequências da globalização para os distintos territórios, lembrando que ela não se manifesta de forma homogênea, apresentando assim, peculiaridades. Benko (1996) busca explicar a "nova organização territorial do capitalismo contemporâneo" (comumente denominada de globalização) através das mutações econômico-sociais em curso, sobretudo com grande intensidade nos países desenvolvidos.

A Globalização provocou a recomposição do mundo (Benko, 1996; 2001), tanto entre nações como intra-nações, estabelecendo novas formas de planejamento territorial, que até meados da década de 1980 estavam sob a tutela do poder central do Estado nacional. No Brasil, a Constituição de 1988 realiza uma nova organização política administrativa entre poder central e entes federados, atribuindoos responsabilidades sociais e econômicas, no entanto essa descentralização do Estado brasileiro trouxe como resultado inúmeras falhas, como por exemplo, a dificuldade de manutenção da política fiscal encarada pelas regiões e municípios.

Essa é uma grande mudança no cerne das políticas territoriais, seja em sua dimensão econômica ou social, pois evidencia a importância dos fatores locais na dinâmica econômica, tornando-as diversificadas e específicas. Nesse contexto de descentralização do Estado e intensificação das trocas mundiais consolidando um novo cenário concorrencial, as proximidades geográfica e organizacional apresentam grande relevância, uma vez que denotam a importância das instituições e da aprendizagem coletiva.

Dessa forma, para Benko (2001) e Benko e Pecqueur (2001), os territórios diferenciam-se entre si na medida que oferecem recursos específicos, intransferíveis e incomparáveis no mercado. Os atores sociais e a política local também desempenham um papel importante nessa diferenciação, já que agem na constituição e na gestão dos recursos presentes no espaço. Esse fato faz com que os territórios sejam diferenciados num cenário global, e tais considerações possibilitam-nos pensar que o efeito Globalização, ou Mundialização como querem os autores, não resulta na homogeneização dos espaços, muito menos do território. Muito pelo contrário, a Globalização acentua o caráter competitivo, fazendo com que os territórios lancem mão de estratégias específicas nesse ambiente concorrencial - glocalização - almejando a diferenciação e a especialização. (Benko e Pecquer,2001).

Considerar a existência e a oferta de recursos específicos por parte dos territórios tem possibilitado o entendimento de que o desenvolvimento é localizado e, portanto, dependente de fatores próprios. Com isso, definiram-se dois tipos de fatores concorrenciais (ativos e recursos), assim como a sua qualificação (genérica ou específica). De forma sucinta, os ativos são os fatores em atividade, enquanto os recursos são os fatores a revelar, a explorar/organizar, ou em outras palavras, são reservas. Quanto a sua qualificação, reproduzimos abaixo o quadro de Benko \& Pecqueur (2001), onde é apresentada a tipologia dos fatores de concorrência espacial. 
Quadro 1: Tipologia dos fatores de concorrência espacial

\begin{tabular}{|c|c|c|}
\hline & Genérico & Específico \\
\hline Recursos & $\begin{array}{l}\text { Fatores de localização não } \\
\text { utilizados, discriminados pelos } \\
\text { preços e custos de transporte } \\
\text { (cálculo, otimização). }\end{array}$ & $\begin{array}{l}\text { Fatores incomensuráveis e } \\
\text { intransferíveis nos quais o valor } \\
\text { depende da organização que os } \\
\text { criou. }\end{array}$ \\
\hline Ativos & $\begin{array}{l}\text { Fatores de localização não } \\
\text { utilizados, discriminados pelos } \\
\text { preços e o custo de transporte } \\
\text { (cálculo, otimização). } \\
\text {-Alocação ótima dos ativos. }\end{array}$ & $\begin{array}{l}\text { Fator comparável onde o valor é } \\
\text { ligado a um uso particular: } \\
\text {-custos de irreversibilidade; } \\
\text { - custos de reatribuição. }\end{array}$ \\
\hline
\end{tabular}

Fonte: Benko \& Pecqueur, 2001

Considerar os ativos e os recursos permite indicar a proximidade geográfica como um fator de competitividade territorial, algo próprio do território, ressaltando que ao pensar a proximidade devese considerar ainda a coordenação entre atores, e estes com as instituições.

Mantendo ainda a perspectiva histórica, Silva $(2009$, p 1) sugere que "toda e qualquer ação que a sociedade desenvolve acontece e materializa-se no território através de relações sociais", ocorrendo nas mais diferenciadas escalas (local, nacional e global), interferindo na vida social, política, econômica e cultural das sociedades, constituindo com isso uma territorialidade, na qual afirma Saquet (2011, p.27) que "as forças sociais efetivam o território no e com o espaço geográfico, centrado nas territorialidades e temporalidades dos indivíduos e emanado delas, condicionando e sendo diretamente determinado por nossa vida cotidiana. Historicamente, formam-se territórios heterogêneos e sobrepostos".

Por fim, o território também pode ser interpretado além de uma rede, constituída de um espaço abstrato de cooperação entre diferentes atores com uma fixação geográfica, para engendrar os processos de criação dos recursos particulares (sociais, econômicos e virtuais), com os objetivos de resolver problemas e apontar para soluções inéditas (Pires, Müller, Verdi, 2006).

\footnotetext{
O território é um produtor de normas e de ordens implícitas que constituem um quadro regulador, um espaço geográfico fundado na proximidade organizacional particular (...). Ele é a constituição de um espaço abstrato de cooperação entre diferentes atores com uma ancoragem geográfica estabelecida, disposta a engendrar os processos de criação dos recursos particulares (...). O território se constitui em um produtor de externalidades complexas, uma escala geográfica de proximidades organizacionais, um espaço de coordenação de ações entre os atores sociais. (PIRES et al, 2006, p.443)
}

Dessa forma o território tende a uma configuração não só material como também institucional, sendo mais adequado considera-lo como um espaço socialmente organizado e configurando-se como um ator importante na promoção do desenvolvimento. O território enquanto categoria analítica permite a compreensão da heterogeneidade e da complexidade do mundo real, das particularidades, das territorialidades, elementos fundamentais ao se pensar um processo de desenvolvimento local. As características culturais e ambientais específicas, seus atores sociais e sua mobilização em torno das diversas estratégias e projetos, assim como a existência e o acesso a recursos estratégicos para o desenvolvimento produtivo e social, são alguns fatores que sensibilizam a sua importância (Pires et al, 2006). 
Se opondo a perspectiva de desenvolvimento verticalizado, ou de cima, Saquet (2011) enfatiza que não é possível desenvolver um país e o seu povo por decretos e/ou assistencialismos. É preciso conceber o desenvolvimento como o resultado de um processo histórico e relacional, de múltiplas determinações econômicas, políticas, culturais e naturais presentes nos territórios.

Em suma, não resta dúvida quão caro e complexo é o conceito de território à Geografia, entendendo-o enquanto um construto social, histórico e espacial, apresentando identidade específica, contornos políticos, econômicos e sociais distintos. A partir disso, atentar-se-á o território enquanto um elemento fundamental para o processo de desenvolvimento regional, incorporando um caráter territorial, com ênfase para suas iniciativas, políticas, possibilidades de avanço, desafios e limites, incluindo a governança como um recurso específico.

\section{A Governança Territorial como instrumento para as estratégias de desenvolvimento}

O conceito de governança aparece nos estudos de Ronald Coase, na década de 1930 e é retomado por Olivier Williamson remetendo a meios operacionais para a coordenação de empresas (1996). Na década de 1980, o conceito é trabalhado pelo Banco Mundial numa análise sobre os Estados e sua capacidade administrativa, estipulando políticas e metas econômicas e sociais para os países subdesenvolvidos. $\mathrm{O}$ Fundo Monetário Internacional aponta, então, para a necessidade da:

(..) promoção da boa governança em todos os seus aspectos, nomeadamente assegurado o primado do Direito, melhorando a eficiência e a responsabilização do setor público e combate à corrupção, como elementos essenciais de um quadro em que as economias podem prosperar". (FMI, 2005 apud PIRES et al., 2011, p.39).

Essas ideias estão dentro de uma mutação conjuntural do pensamento econômico mundial, apoiadas em preceitos das correntes neoliberais da década de 1980, em que defendiam, diante da crise do regime da cumulação fordista, as políticas econômicas territoriais conditas no que Leborgne e Lipietz (1994) chamam de Flexibilidade Defensiva, baseada na desregulamentação salarial, ausência de proteção social, áreas intensamente especializadas e com ampla abertura e concorrência ao mercado mundial. Essa crise no regime de acumulação fordista se desvela no momento de grande instabilidade econômica internacional, nos esgotamentos dos sistemas técnicos predominantes e decadência da produção e consumo de massa, concomitante com os agravamentos das condições sociais e crise no bloco social-territorial (sistema estável de dominação) hegemônico (Boyer, 1994) que orientam as relações de trabalho fordista e modo de vida das classes sociais. Aliado a isso, novas relações inter e intra empresas se desenvolvem sob paradigma da flexibilidade.

Contudo, seguindo o referencial pautado na Escola da Regulação Francesa (M. Aglietta, R. Boyer, G. Benko, A. Lipietz, B. Pecqueur), haveria um novo paradigma de mediação entre as forças do mercado, as políticas do Estado e as necessidades da reprodução social. Vê-se necessário, então, buscar o fortalecimento das instituições socais a partir de "formas intermediárias" apropriadas que articulassem os interesses privados e coletivos, sociais e econômicos, eficientes e com equidade. Nesse novo contexto político-econômico pós-fordista, o Estado não manteria mais sua política keynesiana de proteção e provedor do desenvolvimento, muito menos deixaria a mão invisível do mercado para atuar sobre seu território. Trata-se, então, de uma coordenação política dessas relações produtivas setoriais, quase sempre concentradas espacialmente. Vê-se, então, a necessidade de incentivar a criação de uma rede de articulação entre os atores envolvidos no setor produtivo, fortalecendo suas relações dadas à proximidade territorial. Os "fundamentos da cooperação e da confiança, que resulta 
em redes de cooperação e localidades-regiões-territórios estruturariam uma sólida e configurada divisão social do trabalho" (Dallabrida, Siedenberg e Fernandéz, 2004, p.45). Esses "princípios" seriam, num primeiro momento, os condicionantes necessários para que o desenvolvimento apropriese de uma abordagem territorial.

A partir disso, é destacado o papel da governança territorial, concebida num modelo tripartite (suficiente para abarcar os interesses do mercado, do Estado e da sociedade civil organizada) e multiescalar. A convergência desses interesses é o que dá corpo as estratégias de desenvolvimento, resultado de um processo de governança que segundo Fuini (2010) é "um processo institucionalorganizacional de construção de uma estratégia para compatibilizar os diferentes modos de coordenação entre atores geograficamente próximos em caráter parcial e provisório". (FUINI, 2010, p.11).

Considera-se desse modo que as formas intermediárias podem ser definidas por uma estrutura de governança, a partir da articulação dos atores sociais, concebendo espaço para alguns tipos diferenciados de governabilidade.

Desse modo,

Os conceitos de governança territorial resultam de estratégias dos atores coletivos que se engajam para coordenar ações que permitam resolver problemas locais e regionais oriundos da aglomeração, da especialização ou especificação territorial. Além disso, lançam as seguintes perguntas-chave sobre a regulação social e governança do território: Como os atores lançam mão de determinados meios para construir um padrão de estabilidade social? Como os atores lidam com planos que contemplam opacidades sociais? Como são estabelecidas pelo planejamento as relações entre normas regulatórias, funções operacionais, responsabilidades decisórias e avaliações? (PIRES \& NEDER, 2008, p. 34).

A partir disso, podemos perceber a governança enquanto um recurso específico, pois se trata de um fator de localização incomensurável, não podendo ser deslocado ou transferível, tampouco quantificável, pois é resultado da organização e das estratégias visando solucionar problemas específicos ancorados no território.

Essa concepção se enquadra profundamente no ideário regulacionista, o qual vê na articulação dos atores e na regulação econômica a chave para o desenvolvimento. A relação tripartite dos atores sociais torna-se imprescindível para um reconhecimento e valorização das instâncias locais de poder e vitais para a legitimidade das políticas públicas, além da construção de um novo bloco social.

As formas de organização estariam num jogo de relações entre empregadores, empregados, sindicatos, instituições escolares e administrações locais, isto é, num ambiente institucional aberto, favorável e flexível ao debate. Adverte-se ainda a necessidade de desenvolver essas formas de organização com os contextos culturais de cada território, em conjunto com a interferência regulatória do Estado Nacional, como por exemplo, perante aos mecanismos monetários, formas de concorrência das empresas e satisfação das necessidades sociais. Assim, o espaço torna componente das estratégias de desenvolvimento, representado pela noção de Território.

Portanto,
A governança territorial é definida como o processo institucional-organizacional de construção de uma estratégia para compatibilizar os diferentes modos de coordenação entre atores geograficamente próximos em caráter parcial e provisório atendendo a premissa de resolução de problemas inéditos. Estes compromissos articulam: os atores econômicos entre si e estes com os atores institucionais-sociais e políticos através de "regras do jogo"; e a dimensão local e a global (nacional ou mundial) através das mediações realizadas por atores ancorados no território. (COLLETIS, GILLY et. al, 1999, apud FUINI, 2010, p.39).

É importante frisar sobre o campo de forças existente dentro da governança. Os atores sociais têm 
influências distintas na tomada de decisões e na representatividade não só no território, como também no ambiente organizacional instituído. Na governança territorial originada por um determinado setor produtivo industrial, por exemplo, considera-se a existência de uma diferenciação na hierarquia das empresas, e consequentemente, a influência que cada uma (ou talvez uma central, ou núcleo central) tenha sobre as demais.

As múltiplas combinações possíveis entre o número de parceiros, e a especificidade do capital tecnológico ou humano e a especialização podem provocar uma 'fragmentação' de poder no seio de um sistema produtivo, gerando um amplo leque de poderes e hierarquias dentro da governança. (STORPPER \& HARRISSON, 1994, p.177).

De qualquer forma, essa nova linha de pensamento chama a atenção para as relações e organizações endógenas, onde há uma articulação maior entre atores locais e uma representatividade com o Estado. Ou seja, o território local teria uma autonomia política relativa, a depender da estrutura normativa do Estado e da capacidade de articulação, e um desenvolvimento econômico mais participativo, envolvendo mais atores sociais.

Assim, podemos entender esse processo como um mecanismo de desenvolvimento territorial, a partir de um caráter endógeno:

\begin{abstract}
Nesse sentido, poderíamos definir o desenvolvimento territorial como um processo de mudança social de caráter endógeno, capaz de produzir solidariedade e cidadania, e que possa conduzir de forma integrada e permanente a mudança qualitativa e a melhoria do bem-estar da população de uma localidade ou uma região. Nas estratégias competitivas da globalização, o desenvolvimento territorial é dinamizado por expectativas dos agentes econômicos nas vantagens locacionais, no qual o território é o ator principal do desenvolvimento econômico regional, e as políticas, as organizações e a governança são recursos específicos, a um só tempo disponível ou a ser criado; quando disponível, tratar-se-ia de sua difusão no território, quando ausente, de sua criação (invenção e inovação). Desta forma, o desenvolvimento territorial é o resultado de uma ação coletiva intencional de caráter local, um modo de regulação territorial, portanto, uma ação associada a uma cultura, a um plano e instituições locais, tendo em vista arranjos de regulação das práticas sociais. (PIRES et al, 2006, p.448)
\end{abstract}

A concepção de desenvolvimento territorial finda, então, inserida no campo do desenvolvimento regional/local, sendo concebida como sua alternativa no contexto da globalização. Os grandes planos de desenvolvimentos, centralizados no Estado, sempre atenderam a uma política industrial, que na maioria das vezes ignora as características locais e a organização social de uma região.

Mas o processo de desenvolvimento [territorial] envolve, em certo aspecto, a mobilização de atores, recursos e instituições com forte vínculo espacial, com objetivo de alavancar a competitividade das atividades econômicas locais e propiciar bem-estar social e cultural à comunidade que vive nesse meio. (PIRES et al, 2011, p. 68)

Para Pecqueur (2005, p.12), o "desenvolvimento territorial designa todo processo de mobilização dos atores que leve à elaboração de uma estratégia de adaptação aos limites externos, na base de uma identificação coletiva com uma cultura e um território". De acordo com essa concepção, as estratégias e articulações dos atores, bem como a criação de um ambiente institucional favorável, não são dadas por leis e decretos, mas parte de uma construção histórica, de um território em resposta ao processo de globalização.

No Brasil, isso se torna possível a partir da Constituição Federal de 1988, no momento em que o país se enquadra num contexto de mudança estrutural no pensamento político, provocando uma descentralização das funções da União aos Municípios, concretizada por meio da criação do Ministério da Administração 
e Reforma do Estado (MARE), em 1995. A partir de então, eles adquirem maior autonomia e passam a ter grande responsabilidade em garantir o seu desenvolvimento. As grandes desigualdades regionais que se formaram no país durante seu desenvolvimento histórico viraram lobby da competitividade global, espaço de maximização dos lucros e dos recursos, desvelando o que Santos (1997) chamaria de "Guerra dos Lugares". O recuo do Estado frente às políticas de desenvolvimento efetivo faz agravar a situação de dependência do território frente ao capital.

Dentre as políticas de desenvolvimento territorial, podemos destacar estruturas em diversos setores da economia, seja agrário ou industrial, como os Arranjos Produtivos Locais (APLs), Comitês de Bacias Hidrográficas (CBH), Territórios da Cidadania, Câmaras Setoriais do Agronegócio, Circuitos Turísticos, Conselhos Regionais de Desenvolvimento e até Consórcios Intermunicipais.

\section{As diferentes possibilidades de governança territorial no Brasil: os exemplos dos estados de São Paulo e do Rio Grande do Sul}

Como já explicitado anteriormente, acredita-se que conceber o desenvolvimento territorial a partir da governança seja o caminho mais exitoso, na medida em que permite a participação do local na elaboração e execução das estratégias frente à Globalização. No Brasil são inúmeros os exemplos de estratégias de desenvolvimento territorial promovidas pelo Estado, desde a esfera federal até a municipal, porém, com intensidades de atuação bem distintas uma das outras. A seguir são relatadas de forma sucinta algumas experiências de governança no Brasil, tendo como recorte os estados de São Paulo e o Rio Grande do Sul.

Um estudo do Laboratório de Desenvolvimento Territorial, da Universidade Estadual Paulista (UNESP, campus de Rio Claro), apontou e analisou 18 modalidades de governança territorial no estado de São Paulo, distribuídos em diferentes setores da economia. Embora cada modalidade abarque a sua especificidade, dificuldades, vantagens, acertos e erros, todas estão inseridas em um contexto semelhante de política pública. As modalidades analisadas em São Paulo não são exclusivas, sendo encontradas em todas as regiões do país. É importante frisar que essas estruturas, ou modelos, foram inspirados, com maior ou menor intensidade, nos distritos industriais marshallianos, sistemas produtivos locais franceses (Benko \& Lipietz, 1994) e Clusters (Porter, 1989).

Nas diferentes modalidades de governança, o Estado possui atuações específicas, sendo mais presente em algumas e praticamente ausente em outras. Situações como os APLs e as Câmaras Setoriais do Agronegócio, o Estado age na formação e no monitoramento da governança, criação de políticas públicas com parceria de atores privados e capitação de recursos de origem nacional e internacional, como o Plano de Competitividade dos APLs do Banco Interamericano de Desenvolvimento (BID).

Os APLs tomam como característica básica a sua organização, que se concebe por meio de aglomerações de empresas localizadas em um mesmo contexto territorial, apresentando especialização produtiva, mantendo ainda algum vínculo de interação, articulação e cooperação entre si e com outros atores locais, como governo municipal, além de outras instâncias (estadual e federal), associações empresariais, instituições de crédito, universidades e outros centros de pesquisa e desenvolvimento (FUINI, 2010).

No Brasil, o termo passou a ser muito utilizado na década de 1990, principalmente pelo governo federal, incluindo os APLs dentre as prioridades da política de desenvolvimento do país. Para avançar com os estudos sobre o funcionamento, o desenvolvimento dessas aglomerações e a sua eficácia no desenvolvimento regional, foi criado o Grupo de Trabalho Permanente para APLs (GTP-APL), que tem o papel de coordenar as ações dos arranjos pelo país, vinculado ao Ministério do Desenvolvimento, 
Indústria e Comércio Exterior (MDIC) com a participação de 33 instituições públicas e privadas. A Rede de Pesquisa em Sistemas Produtivos e Inovativos Locais (REDESIST), grupo de pesquisa criado em 1997 e sediada no Instituto de Economia da Universidade Federal do Rio de Janeiro (IE-UFRJ), elaborou o principal conceito de APL, usado pelo MDIC. Segundo o grupo os APLs são:

(...) aglomerações territoriais de agentes econômicos, políticos e sociais - com foco em um conjunto específico de atividades econômicas - que apresentam vínculos mesmo que incipientes. Geralmente envolvem a participação e a interação de empresas - que podem ser desde produtoras de bens e serviços finais até fornecedoras de insumos e equipamentos, prestadoras de consultoria e serviços, comercializadoras, clientes, entre outros - e suas variadas formas de representação e associação. Incluem também diversas outras organizações públicas e privadas voltadas para: formação e capacitação de recursos humanos, como escolas técnicas e universidades; pesquisa, desenvolvimento e engenharia; política, promoção e financiamento (REDESIST, p.3, 2003).

O grupo destaca que a formação dos arranjos está associada às trajetórias históricas de construção de identidades e de formação de vínculos territoriais, a partir de uma base social, cultural, política e econômica comum. Dessa maneira, torna-se necessária para o bom desenvolvimento do arranjo a existência de ambientes favoráveis à interação, à cooperação e à confiança entre os atores.

Outra modalidade de governança existente são as Câmaras Setoriais do Agronegócio. Inicialmente elas surgiram no setor automobilístico, no final da década de 1980, onde os sindicatos das montadoras do ABC Paulista passaram a ampliar o diálogo com as indústrias, abrindo margem para a negociação, deixando pela primeira vez o discurso ideológico em segundo plano. Com essa primeira demonstração satisfatória, as Câmaras Setoriais ganham força no Brasil, principalmente no setor agrícola, cujo mesmo passava por um momento de liberalização econômica. A modernização do campo já avançava no território nacional valorizando a mecanização e a presença de capital externo, que culminaram num aumento da concentração de terras e uma maior desigualdade, tanto no meio rural quanto no urbano (dado pelo forte êxodo rural).

Em 1991 aparecem as primeiras câmaras do agronegócio, a fim de criar esse espaço de negociação e planejamento, no intuito de aumentar competividade a partir de políticas públicas setoriais. Segundo Staduto (2007), as câmaras setoriais, a partir da primeira legislação em 1988, apareceram como mecanismo de suprir as funções antes ocupadas pelo Estado, na medida em que, uma vez instituídas, elas buscar-se-iam um ambiente institucional favorável para o setor correspondente. No estado de São Paulo, esse modelo é visualizado a partir de 29 Câmaras, desde setores agrícolas tradicionais, como vinicultura, produção de lácteos, frutas e até ofensivos agrícolas.

No Brasil, o Ministério da Agricultura, Pecuária e Abastecimento (MAPA) coordena 37 Câmaras Setoriais e Temáticas concebendo-as como um instrumento consultivo na identificação de oportunidades ao desenvolvimento das cadeias produtivas, tanto para o desenvolvimento tecnológico e a inovação do setor quanto para aprimorar a articulação dos agentes públicos e privados na formulação de políticas interesse comum, visando à atuação sistêmica e integrada dos diferentes segmentos produtivos (MAPA, 2014). Geralmente, partem de aglomerações agrícolas e industriais de micro, pequeno e médio porte, mantendo sempre uma relação intrínseca e histórica/cultural com o local.

Há que se destacar também as modalidades de governança onde o Estado figura mais incisivamente, participando ativamente no funcionamento da governança e exercendo uma atuação multiescalar e transsetorial, como o caso dos Conselhos Regionais de Desenvolvimento (COREDES) e dos Comitês de Bacia Hidrográfica (CBH). Os primeiros surgiram no início dos 1990, com a finalidade de atenuar as desigualdades intrarregionais na macrorregião sul, sobretudo no Rio Grande do Sul, primeira 
unidade federativa a implantar essa política. Eles aparecem como uma nova forma institucional e de escala territorial na gestão pública entre o Estado e o município (PIRES et al, 2011). Já os Comitês de Bacias Hidrográficas (CBH), existentes a partir da Constituição de 1988, configuram-se como instâncias públicas com a finalidade de elaborar políticas para o uso dos recursos hídricos. Os membros que compõem o colegiado são escolhidos entre diversos setores econômicos - que fazem usufruto de reservatórios lacustres ou captação de águas fluviais ou em aquíferos - além das organizações civis e do poder público regional representado pelos prefeitos dos municípios. Dentre os seus objetivos práticos, o CBH procura elaborar Plano de Recursos Hídricos da Bacia (PRHB) além da resolução de conflitos locais pelo uso da água (CBH, 2014).

Por tudo isso, a partir desse despretensioso texto é possível notar a diversidade de modalidade de governança territorial existentes no Brasil, a partir de alguns exemplos presentes nos estados de São Paulo e Rio Grande do Sul, demonstrando os novos aspectos, características e comportamentos sobre o qual vem se desenvolvendo os projetos e as iniciativas de desenvolvimento regional/territorial. É importante a distinção de cada modalidade, proporcionada graças à essência e o propósito de cada uma delas, assim como o grau de organização e comprometimento dos atores envolvidos, responsáveis pelo sucesso ou não da governança.

\section{CONSIDERAÇÕES FINAIS: o território como fundamento para o desenvolvimento}

O conceito de território não é exclusivo da ciência Geográfica, estando presente também na Ciência Política, Economia e Sociologia. Especificamente na Geografia, é concebido como um conceito heterogêneo, com diferentes definições e usos. Após as explanações, é possível auferir que o território, enquanto uma construção material e imaterial das relações sociais durante o processo histórico, possibilita compreender a complexidade das relações sociais e das estruturas institucionais definidas espacialmente, seja local ou global.

O termo desenvolvimento territorial permite conceber o conceito de território como promotor do recurso específico, instância fundamental de ação política, mobilização e criação de uma rede de cooperação. A governança aparece nesse momento como um mecanismo potencial para essa mobilização entre atores, exemplificados nas modalidades apresentadas no texto como APLs, Câmaras Setoriais, Conselhos Regionais e Comitês de Bacias Hidrográficas. É sempre importante frisar que a consolidação de um modelo de governança não esconde o ambiente de concorrência e conflito entre os atores envolvidos territorialmente, nem as particularidades e limitações normativas ou estruturais do local, mas possibilitar um caminho para a mediação desses interesses coletivos comuns capazes de garantir uma autonomia política e fortalecimento das atividades econômicas perante a competitividade posta na Globalização onde as grandes empresas globais tendem a solapar as potencialidades sociais, econômicas e culturais, impossibilitando um desenvolvimento efetivo no (e para) o local.

\section{REFERÊNCIAS}

BENKO, G. A recomposição dos espaços. Interações - Revista Internacional de Desenvolvimento Local. Universidade Católica Dom Bosco/MS, v.1, n. 2, p. 7-12, mar. 2001.

BENKO, G. Economia, Espaço e Globalização na aurora do século XXI. 2. ed. São Paulo: Editora Hucitec, 1996. 
BENKO, G., \& LIPIETZ, A. As Regiões Ganhadoras - Distritos e Redes: Os novos paradigmas da geografia econômica. Lisboa: Celta Editora, 1994.

BENKO, G.; PECQUEUR, B. Os recursos de territórios e os territórios de recursos. Geosul - Revista do Departamento de Geociências, Florianópolis, v. 16, n. 32, p. 31-50, jul. /dez, 2001.

BOYER, R. As alternativas ao fordismo. In. BENKO, G., \& LIPIETZ, A. As Regiões Ganhadoras Distritos e Redes: Os novos paradigmas da geografia econômica. Lisboa: Celta Editora, 1994.

BOYER, R. A Teoria da Regulação: uma Análise crítica. São Paulo: Nobel, 1990.

BRASIL. Ministério da Agricultura, Pecuária e Abastecimento. As Câmaras Setoriais e Temáticas. Recuperado em 10 fevereiro, 2014, de http://www.agricultura.gov.br/camaras-setoriais-e-tematicas.

CBH. Comitê de bacia Hidrográfica. Recuperado em 24 janeiro, 2014, de http://www.cbh.gov.br/

DALLABRIDA, V. R.; SIEDENBERG, D. R. \& FERNANDÉZ, V. R. Desenvolvimento a Partir da Perspectiva Territorial. Desenvolvimento em Questão. Ijuí: v. 2, n. 4 ,jul./dez, 2004.

DALLABRIDA, V. R. Governança territorial: Um primeiro passo na construção de uma proposta teórico-metodológica. SEMINÁRIO INTERNACIONAL SOBRE DESENVOLVIMENTO LOCAL. , 3. Santa Cruz do Sul: Unisc, 2006.

DALLABRIDA, V. R \& BECKER, D. F. Dinâmica Territorial do Desenvolvimento. In D. F. Becker. \& M.L. Wittmann, M. L. (Eds). Desenvolvimento Regional: abordagens interdisciplinares. Santa Cruz do Sul: Edunisc, 2003.

FUINI, L. L. Manifestações da governança territorial no Brasil: uma análise do Circuito das Águas Paulistas e do Circuito das Malhas do Sul de Minhas Gerais, 2010. Rio Claro. Tese (Doutorado). IGCE/UNESP, 2010.

HAESBAERT, R. Des-caminhos e perspectivas do território. In: RIBAS, A.D; SPOSITO, E.S; SAQUET, M.A. Território e desenvolvimento: diferentes abordagens. Francisco Beltrão: Unioeste, 2004.

HAESBAERT, R. \& LIMONAD, E. O Território em tempos de globalização. Revista Geo UERJ.v. 3,n.5, p.7-20. Rio de Janeiro: Depto de Geografia -UERJ, 1999.

LEBORGNE, D; LIPIETZ, A. Flexibilidade Ofensiva, Flexibilidade Defensiva. In. BENKO, G., \& LIPIETZ, A. As Regiões Ganhadoras - Distritos e Redes: os novos paradigmas da geografia econômica. Lisboa: Celta Editora, 1994.

MOREIRA, R. Conceitos, categorias e princípios lógicos para o método e o ensino da Geografia. Pensar e Ser em Geografia. .São Paulo: Contexto, 2007.

PECQUEUR, B. O desenvolvimento territorial: Uma nova abordagem dos processos de desenvolvimento 
para as economias do Sul. Raízes. Campina Grande, v.24, n.1-2, p. 10-22, jan./dez. 2005.

PIRES, E. L. S. A nova política nacional de desenvolvimento territorial em questão. PPP - Planejamento e Políticas Públicas, Brasília: IPEA, 2010.

PIRES, E. L. S. et al. Governança Territorial: Conceitos, Fatos e Modalidades. Rio Claro: Editora da Pós- graduação em Geografia/ IGCE/ UNESP, 2011.

PIRES, E. L.; NEDER, R. T. A governança territorial no Brasil: As instituições, os fatos e os mitos. Geografia e Pesquisa, Ourinhos/SP, Unesp, v. 2, n. 2, p. 31-45, jul/dez. 2008.

PIRES, E. L. S.; MÜLLER, G. \& VERDI, A. Instituições, territórios e desenvolvimento local: delineamento preliminar dos aspectos teóricos e morfológicos. Geografia - Associação de Geografia Teorética, v. 31, n. 3, p. 437-454, set./dez, Rio Claro, 2006.

PIRES, E. L. S. \& VERDI, A. R. As dinâmicas territoriais locais na globalização: aspectos conceituais e metodológicos. Geosul, Florianópolis, v. 23, n. 46, p 33-53, jul./dez, 2008.

PORTER, M. E. A vantagem competitiva das nações. Rio de Janeiro: Campus, 1993.

REDESIST, Rede de Pesquisa em Sistemas Produtivos e Inovativos Locais. Glossário de Arranjos e Sistemas produtivos e Inovativos Locais., de Disponível em:http://portalapl.ibict.br/export/sites/apl/ galerias/arquivos noticias/glossario.pdf. Acesso em 20 abr. 2014.

RIBAS, A. D.; SPOSITO, E. S, \& SAQUET, M. A. Território e desenvolvimento: diferentes abordagens. 3. Ed. Francisco Beltrão: Editora Unioeste, 2005.

SADER, E. 10 Anos de governos pós-neoliberais no Brasil: Lula e Dilma. São Paulo: Boitempo; Rio de Janeiro: FLACSO Brasil, 2013.

SAMPAIO, P. de. A. Para além da ambiguidade - uma reflexão histórica sobre constituição de 1988. ENCONTRO REGIONAL DE ESTUDANTES DE DIREITO E ENCONTRO REGIONAL DE ASSESSORIA JURÍDICA UNIVERSITÁRIA., 20: 20 anos de Constituição. Parabéns! Por quê? Crato: Fundação Araripe, 2008.

SAQUET, M. A. Proposições para estudos territoriais. Revista Geografia. Universidade Estadual do Oeste do Paraná Francisco Beltrão, V.8, n.15, 15, Beltrão, 2006.

SAQUET, M.A. Por uma Geografia das territorialidades e das temporalidades: uma concepção multidimensional voltada para a cooperação e para o desenvolvimento territorial. 1ed. São Paulo: Outras Expressões, 2011.

SANTOS, M.O retorno do território. In. SANTOS, M. Território, globalização e fragmentação. São Paulo: Ed. Hucitec, 1994.

A Natureza do Espaço: Técnica e Tempo. Razão e Emoção. 2 ed. São Paulo: 
Hucitec, 1997.

. Território, globalização e fragmentação. São Paulo: Ed. Hucitec, 1998.

. O território e o saber local: algumas categorias de análise. Cadernos do IPPUR, v.

13, n. 2, p. 15-26, Rio de Janeiro, 1999.

SANTOS, M. \& SILVEIRA, O Brasil: Território e Sociedade no início do século XXI. São Paulo: Editora Record, 2001.

SILVA, J.M.P. Poder, governo e território na sociedade contemporânea. Série Estudos e Ensaios/ Ciências Sociais. FLACSO - BRASIL. 2009. Disponível em: http://www.flacso.org.br/portal/pdf/serie_ estudos_ensaios/Joao_Palheta.pdf. Acessado em: 20 de janeiro de 2012.

STADUTO, J. A. R. et al. As Câmaras Setoriais do agronegócio brasileiro. CONGRESSO DA SOCIEDADE BRASILEIRA DE ECONOMIA, ADMINISTRAÇÃO RURAL. 45.Anais..., Londrina: SOBER, 2007.

STORPER \& HARRISSON, 1994, Flexibilidade, Hierarquia e Desenvolvimento Regional. In Benko, G., \& Lipietz, A. As Regiões Ganhadoras - Distritos e Redes: os novos paradigmas da geografia econômica. Lisboa: Celta Editora, 1994.

TOPPAN, R. N. Território e Desenvolvimento Local: A Governança Territorial da Câmara Setorial da Uva e do Vinho do Estado de São Paulo. Relatório Científico. Rio Claro: Fundação de Amparo à Pesquisa do Estado de São Paulo, 2013.

WILLIAMSON, O. E. The mechanisms of governance. New York, Oxford University Press, 1996. 